\title{
Age and Heat Exposure-Dependent Changes in Antioxidant Enzymes Activities in Rat's Liver and Brain Mitochondria: Role of $\alpha$-tocopherol
}

\author{
V. STOJKOVSKI ${ }^{2}$, N. HADZI-PETRUSHEV ${ }^{1}$, V. ILIESKI ${ }^{2}$, R. SOPI ${ }^{1}$, I. GJORGOSKI ${ }^{1}$, \\ D. MITROV ${ }^{2}$, N. JANKULOVSKI ${ }^{3}$, M. MLADENOV ${ }^{1}$ \\ ${ }^{1}$ Faculty of Natural Sciences and Mathematics, Institute of Biology, "Ss. Cyril and Methodius" \\ University, Skopje, Macedonia, ${ }^{2}$ Faculty of Veterinary Medicine, "Ss. Cyril and Methodius" \\ University, Skopje, Macedonia, ${ }^{3}$ Faculty of Medicine, "Ss. Cyril and Methodius" University, \\ Skopje, Macedonia
}

Received January 21, 2013

Accepted May 15, 2013

On-line September 10, 2013

\section{Summary}

To investigate the role of mitochondrial antioxidant capacity during increased susceptibility to heat accompanied by the aging, young and aged Wistar rats were exposed on heat for $60 \mathrm{~min}$. After heat exposure, hepatic and brain mitochondria were isolated. Our results revealed changes in antioxidant enzyme activities in liver and brain mitochondria from young and to a greater extent in aged rats. Our measurements of MnSOD, GPx and GR activity indicate greater reactive oxygen species production from the mitochondria of aged heat exposed in comparison to young heat exposed rats. Also in the aged rats, the effect of a-tocopherol treatment in the prevention of oxidative stress occurred as a result of heat exposure, is less pronounced. Taken together, our data suggest that mitochondria in aged rats are more vulnerable and less able to prevent oxidative changes that occur in response to acute heat exposure.

\section{Key words}

Antioxidant enzymes • Mitochondria • Liver • Brain • Aging • Heat exposure

\section{Corresponding author}

M. Mladenov, Faculty of Natural Sciences and Mathematics, Institute of Biology, "Sts, Cyril and Methodius" University, P.O. Box 162, Skopje 1000, Macedonia. Fax: +389 23228141. E-mail: mitkom@pmf.ukim.mk

\section{Introduction}

According "mitochondrial theory of aging", mitochondria are incorporated as critical components that regulate aging. This theory postulates that electrons from the mitochondrial electron transport chain (ETC) produce reactive oxygen species (ROS), which damage components of the ETC, leading to a cyclic increase in intracellular ROS levels and a decline in mitochondrial function (Wallace 2005). The same author published that such a declined mitochondrial function could be the result of superoxide anions, whose production is induced by different stressors. On the other hand, ameliorative mechanism responsible for correction of superoxide anions, includes conversion to membrane-permeable hydrogen peroxide $\left(\mathrm{H}_{2} \mathrm{O}_{2}\right)$ by the action of mitochondrial superoxide dismutase (SOD), dominantly present in the matrix as a (MnSOD) and in inter-membrane space as a (CuZnSOD) (Morrison et al. 2005, Aydin et al. 2010, Ozturk et al. 2012). Further, $\mathrm{H}_{2} \mathrm{O}_{2}$ can be reduced to water by glutathione peroxidase (GPx) using electrons from glutathione (GSH) (Jaeschke 1990). The last reaction ends with oxidation of GSH into glutathione disulfide (GSSG), as an index for increased $\mathrm{H}_{2} \mathrm{O}_{2}$ formation in mitochondria (Jaeschke 1990, Knight et al. 2001), although extra-mitochondrial sources of ROS cannot be excluded. In the same study (Knight et al. 2001), reported that despite GPx, catalase (CAT) could be also involved in neutralization of $\mathrm{H}_{2} \mathrm{O}_{2}$ produced during different acute stress conditions. Hence, they 
promote CAT as an important player in the regulation of red-ox balance. Another study (Olafsdottir and Reed 1988) indicates that the activity of glutathione reductase (GR) is especially important in preventing protein oxidation in mitochondria during acute stress. However, our review of recently published research showed that there are no scientific data supporting the studies about the determination of mitochondrial enzyme red-ox mechanisms induced during acute heat exposure and in function of aging in the same time.

The $\alpha$-tocopherol as a lipid-soluble antioxidant, effectively prevents lipid peroxidation (Knight et al. 2001). Few studies, demonstrated that increased level of $\alpha$-tocopherol in mitochondria is critical against oxidative stress in the same mitochondria (Fariss et al. 2001, Zhang et al. 2001a, Fariss and Zhang 2003). In fact, recent findings indicate that enrichment of mitochondria with protective $\alpha$-tocopherol, weakens production of ROS and antioxidant enzyme activities, especially in hepatic mitochondria (Chow et al. 1999, Zhang et al. 2001b). Nevertheless, up to date there are no studies that examine preventive role of $\alpha$-tocopherol on mitochondrial level, during acute heat exposure associated with different ages.

Considering that generation of ROS typically associated with the application of heat stress is exaggerated with advancing age (Hadzi-Petrushev et al. 2011), our approach was to determine preventive role of $\alpha$-tocopherol on mitochondrial antioxidant enzymes, influenced by acute heat exposure, in rats of different ages. Our experiments were focused on liver and brain, because they are very active metabolically, contain the largest number of mitochondria and show age-related increased ROS production (Yen et al. 1994). Therefore, the objective of this investigation was to test hypothesis that $\alpha$-tocopherol, due to its ROS scavenging activity, would aid the maintenance of antioxidant capacity in mitochondria and prevent some of age and heat stress related changes in antioxidant enzyme activities.

\section{Material and Methods}

\section{Animals and experimental design}

All experimental procedures were conducted in accordance with the Guiding Principles for Care and Use of Laboratory Animals approved by the Macedonian Center for Bioethics. All protocols were approved by the Animal Ethics Committee of the University "Sts. Cyril and Methodius", Skopje, R. Macedonia in accordance with the International Guiding Principles for Biomedical
Research Involving Animals, as issued by the Council for International Organizations of Medical Sciences. Anesthetics were applied according to standards given by the guide of the EC Directive 86/609/EEC. Animals were anesthetized with an intraperitoneal injection of (100 mg kg-1 b.wt., thiopentane sodium BP; RhonePoulenc Rorer Limited, Nenagh, Co Tipperary, Ireland). Male Wistar rats $(n=64)$ were used for all protocols and were maintained on a 12:12 light: dark cycle and fed with rat chow containing $0 \mathrm{mg} \alpha$-tocopherol and water $a d$ libitum. All animals were divided into eight groups. Four groups which consisted of 15 days old rats were further divided depending on treatment with $\alpha$-tocopherol and heat exposure into: young placebo heat-unexposed $(n=8$; YP), young heat-exposed ( $n=8 ; Y H)$, young $\alpha$-tocopherol treated heat unexposed $(\mathrm{n}=8$; YT $)$ and young $\alpha$-tocopherol treated heat-exposed $(\mathrm{n}=8$; YTH) rats. The other four groups included 12 months aged rats were divided in a similar manner into: aged placebo heat unexposed $(n=8 ; A P)$, aged heat-exposed $(n=8 ; A H)$, aged $\alpha$-tocopherol treated heat unexposed $(n=8 ; A T)$ and aged $\alpha$-tocopherol treated heat-exposed $(\mathrm{n}=8 ; \mathrm{ATH})$ rats.

\section{In vivo treatment and heat exposure}

For 21 consecutive days rats in $\alpha$-tocopherol groups were treated intra-gastrally with vegetable oil containing $\alpha$-tocopherol ( $0.32 \mathrm{IU} \mathrm{kg}^{-1}$, Sigma) and rats in placebo groups were injected intra-gastrally with vegetable oil containing $0 \mathrm{mg} \alpha$-tocopherol. Previously was shown that used dose of $\alpha$-tocopherol significantly increase the levels of $\alpha$-tocopherol in several tissues, including liver and plasma in mice (Berg et al. 2004, Godbout et al. 2004a,b). During the treatment period all animals were housed at $20 \pm 2{ }^{\circ} \mathrm{C}$.

Heat exposed rats were housed individually in a special heated chamber maintaining a constant temperature of $40 \pm 0.5^{\circ} \mathrm{C}$ and relative air humidity of 40-50\%. During heat exposure, rectal (rec) temperatures $\left(T_{\text {rec }}\right)$ were read by an electric thermometer (Ellab TE 3) every $10 \mathrm{~min}$ until it reached the temperature of the chamber, then the readings continued to be taken in $2 \mathrm{~min}$ intervals. The temperatures were recorded at various distances from the anal sphincter in dependence from age. Thermistor probes were inserted 25 or $45 \mathrm{~mm}$ Lomax (1966), into the rectum of the young or aged rats, respectively. The exposure was terminated in terms of 60 min (Aprille and Austin 1981, Hadzi-Petrushev et al. 2012). 


\section{Isolation of mitochondria}

Animals were sacrificed by ether narcosis, and the appropriate organs were immediately removed. Liver mitochondria were isolated using the method described by Olafsdottir and Reed (1988). Tissues were homogenized in ice-cold buffer containing $1 \mathrm{mM}$ Tris- $\mathrm{HCl}, 0.25 \mathrm{M}$ sucrose and $1 \mathrm{mM}$ EDTA, $\mathrm{pH}$ 7.4. The homogenate was first centrifuged at $600 \mathrm{~g}$ for $10 \mathrm{~min}$ at $4{ }^{\circ} \mathrm{C}$ and the supernatant fractions were collected and further centrifuged at $8000 \mathrm{~g}$ for $20 \mathrm{~min}$ at $4{ }^{\circ} \mathrm{C}$ in order to pellet the mitochondria. After washing with $0.25 \mathrm{M}$ sucrose buffer containing $1 \mathrm{mM}$ EDTA and $1 \mathrm{mM}$ Tris-HCl, $\mathrm{pH} 7.4$, mitochondrial pellets were resuspended in $0.25 \mathrm{M}$ sucrose buffer containing $1 \mathrm{mM}$ Tris- $\mathrm{HCl}$, $\mathrm{pH} 7.4$ and stored at $-80^{\circ} \mathrm{C}$ until further analyses.

Mitochondria in the brain were isolated using the method described by Carretero et al. (2009) and Ozturk et al. (2012). Tissues were homogenized in ice-cold buffer containing $0.3 \mathrm{M}$ mannitol and $0.1 \mathrm{mM}$ EDTA, pH 7.4. The homogenates were first centrifuged at $600 \mathrm{~g}$ for $10 \mathrm{~min}$ at $4{ }^{\circ} \mathrm{C}$ and the supernatant fractions were collected and further centrifuged at $10000 \mathrm{~g}$ for $10 \mathrm{~min}$ at $4{ }^{\circ} \mathrm{C}$ in order to obtain the brain mitochondria. The mitochondrial pellets were washed three times with $0.25 \mathrm{M}$ sucrose buffer containing 0.1 mM EDTA, pH 7.4, resuspended in $0.25 \mathrm{M}$ sucrose buffer, $\mathrm{pH} 7.4$ and stored at $-80{ }^{\circ} \mathrm{C}$ until further analyses. Mitochondria were disrupted by twice freezing and thawing before analyses.

\section{Assay for MnSOD activity}

MnSOD activity was determined according to the method described by Del Maestro et al. (1983) based on the ability of MnSOD to inhibit the auto-oxidation of pyrogallol. The reaction mixture consisted of $50 \mathrm{mM}$ Tris-HCl, $\mathrm{pH} 8.2,1 \mathrm{mM}$ diethylenetriamine pentaacetic acid, and sample. CuZnSOD activity was inhibited by the addition of $0.1 \mathrm{M} \mathrm{NaCN}$ to the assay buffer for $15 \mathrm{~min}$. The reaction was initiated by the addition of pyrogallol (final concentration of $0.2 \mathrm{mM}$ ) and the absorbance measured kinetically at $420 \mathrm{~nm}\left(25^{\circ} \mathrm{C}\right)$ for $3 \mathrm{~min}$. One unit of activity is defined as the amount of sample needed to inhibit pyrogallol oxidation by $50 \%$. The final results were expressed as $\mathrm{U} / \mathrm{mg}$ protein.

\section{Assay for total GPx activity}

The activity of GPx was determined according to Lawrence and Burk (1976) with some modifications. The activity was assayed by following the oxidation of $\mathrm{NADPH}$ at $340 \mathrm{~nm}$ for $3 \mathrm{~min}\left(25^{\circ} \mathrm{C}\right)$ in the presence of
GR and GSH. The reaction mixtures containing $50 \mathrm{mM}$ potassium phosphate, $\mathrm{pH} 7.0,1 \mathrm{mM}$ sodium azide, $2 \mathrm{mM}$ GSH, $0.2 \mathrm{mM}$ NADPH, $1 \mathrm{U} / \mathrm{ml}$ GR, $1.5 \mathrm{mM}$ cumene hydroperoxide and samples were incubated at $25^{\circ} \mathrm{C}$ for $5 \mathrm{~min}$. The reaction was initiated by the addition of cumene hydroperoxide. The unit was defined as the oxidation of $1 \mu \mathrm{mol}$ of NADPH/min. Final results were expressed as $\mathrm{U} / \mathrm{mg}$ protein.

\section{Assay for GR activity}

The rate of oxidation of NADPH by GSSG at $30{ }^{\circ} \mathrm{C}$ was used as a standard measure of GR activity Racker (1955). The reaction system contained $1 \mathrm{mM}$ GSSG, $0.1 \mathrm{mM}$ NADPH, $0.5 \mathrm{mM}$ EDTA, $100 \mathrm{mM}$ potassium phosphate buffer, $\mathrm{pH} 7.5$ and a suitable amount of sample. The oxidation of $1 \mu \mathrm{mol}$ of $\mathrm{NADPH} / \mathrm{min}$ was defined as a unit of glutathione reductase activity. The specific activity was expressed as $\mathrm{U} / \mathrm{mg}$ protein.

The mitochondrial protein content was determined using the method described by Lowry et al. (1951). Analyses for MnSOD, GPx, and GR were carried out on the ELISA reader (Bio-Rad), while analyses for protein concentration were carried out on the spectrophotometer Cintra 6.

\section{Statistical analysis}

Variables are reported as mean values \pm standard deviation (SD). Data were analyzed by 3 way ANOVA. The means were compared using the Tukey test. Multiple linear regression analysis was performed to assess independent predictor of GPx and GR activity. Differences were considered significant at a level of $p<0.05$. The statistical software package SPSS 16.0 for Windows (SPSS, Chicago, IL, USA) was used for all analyses.

\section{Results}

Time course of rectal temperature dynamics in heatexposed animals

The time course of rectal temperature dynamic in heat-exposed animals is well documented in our previous study (Mladenov et al. 2006). In this study we employed the same conditions with shortened duration of exposure. In fact, we terminated exposure in terms of 60 min, during which time the rats achieved a second phase known as temperature plateau. Our expectation was that this duration of exposition could be enough to throw 
Table 1. Rectal temperature changes in heat-exposed animals.

\begin{tabular}{llcccc}
\hline Group & $\begin{array}{c}\mathbf{T}_{\text {rec }}\left({ }^{\mathbf{0}} \mathbf{C}\right) \\
\pm \mathbf{S D}\end{array}$ & $\boldsymbol{P}$ & $\begin{array}{c}\text { After 30 min } \\
\text { of exposure }\end{array}$ & $\begin{array}{c}\text { After 60 min } \\
\text { of exposure }\end{array}$ \\
\hline$Y H$ & $36.8 \pm 0.41$ & $<0.05$ & $40.1 \pm 0.32$ & $>0.05$ & $40.6 \pm 0.22$ \\
$Y T H$ & $36.6 \pm 0.38$ & $<0.05$ & $40.4 \pm 0.28$ & $>0.05$ & $40.5 \pm 0.19$ \\
$A H$ & $36.7 \pm 0.41$ & $<0.05$ & $39.9 \pm 0.34$ & $>0.05$ & $40.3 \pm 0.22$ \\
$A T H$ & $36.5 \pm 0.51$ & $<0.05$ & $39.6 \pm 0.21$ & $>0.05$ & $40.2 \pm 0.13$ \\
\hline
\end{tabular}

Animals were exposed at $40^{\circ} \mathrm{C}$. $P$ value represents modified least squares difference (Bonferroni) test. Data are presented as mean \pm SD. YH - young heat exposed; YTH - young a-tocopherol treated heat-exposed; AH - aged heat-exposed; ATH - aged a-tocopherol treated heat-exposed rats.

the rats in "alarming" high-temperature state, as a suitable condition for investigation of early mitochondrial events of temperature shock. Our results revealed that after $30 \mathrm{~min}$ of heat exposure as a transitional point between primary hypertermy and temperature plateau (Mladenov et al. 2008), $\alpha$-tocopherol treatment did not cause significant changes $(\mathrm{p}<0.092$ and 0.104$)$ in rectal temperatures in both young and aged animal groups, when compared to placebo rats. Rectal temperatures $30 \mathrm{~min}$ after heat exposure significantly increased in both young and aged animals $(\mathrm{p}<0.05$, respectively) in comparison to their unexposed counterparts (Table 1). The rectal temperatures for both treated and placebo heat unexposed groups, were also measured according to the same protocol applied for heat exposed rats and there were no changes in rectal dynamics during proposed interval of measurement (results are not shown).

\section{Influence of aging, $\alpha$-tocopherol treatment and acute heat exposure on MnSOD activity}

MnSOD activity in the liver and brain mitochondria of aged animals was significantly higher compared to the values obtained from young rats $(\mathrm{p}<0.05$ and 0.001 , respectively). $\alpha$-tocopherol treatment caused significant decrease of MnSOD activity in brain mitochondria of both, young and aged $(p<0.05$, respectively), and only in liver mitochondria of the aged rats $(p<0.05)$. The preventive effect of $\alpha$-tocopherol treatment was also observed for MnSOD activity in liver mitochondria of heat-exposed rats $(p<0.05$, for both young and aged, respectively). However, the activity of MnSOD in brain mitochondria of heat-exposed $\alpha$-tocopherol treated rats wasn't changed in comparison to the activity in untreated heat-exposed rats, regardless of age $(p=0.672$ and $p=0.534)$. On average, the brain mitochondria showed lower MnSOD activity compared to the liver mitochondria (Fig. 1A and 1B).

Influence of aging, $\alpha$-tocopherol treatment and acute heat exposure on GPx activity

Data presented in Figure 2A and 2B shows that aging caused significant increase in GPx activity in liver and brain mitochondria ( $\mathrm{p}<0.05$ and 0.001 , respectively). In the brain mitochondria from aged rats, were registered significant heat-induced deterioration in the GPx activity $(\mathrm{p}<0.05)$. The treatment with $\alpha$-tocopherol caused significant decreasing of GPx activity in aged liver and brain mitochondria in both ages $(\mathrm{p}<0.05$ respectively). Similarly to relations observed in MnSOD activity, the brain mitochondria showed lower average GPx activity compared to the liver mitochondria.

Influence of aging, $\alpha$-tocopherol treatment and acute heat exposure on GR activity

Aged rats showed significantly higher GR activity in liver and brain mitochondria compared to their younger counterparts $(\mathrm{p}<0.001$, for both). Acute heat exposure caused a significant elevation of GR activity in aged brain and liver mitochondria of both aging groups ( $<<0.05$, respectively). The $\alpha$-tocopherol treatment effectively prevents this change in liver mitochondria at both heat-exposed aging groups, which can be concluded checking up the pairs YH/YTH and AH/ATH (Fig. 3A). In brain compartment, the enzyme activity in ATH was significantly lower in comparison with $\mathrm{AH}$, while the means of AT and ATH differ non-significantly $(p=0.121)$ (Fig. 3B). On overall, GR activity in liver mitochondria was higher than GR activity in brain mitochondria (Fig. 3A and 3B). 

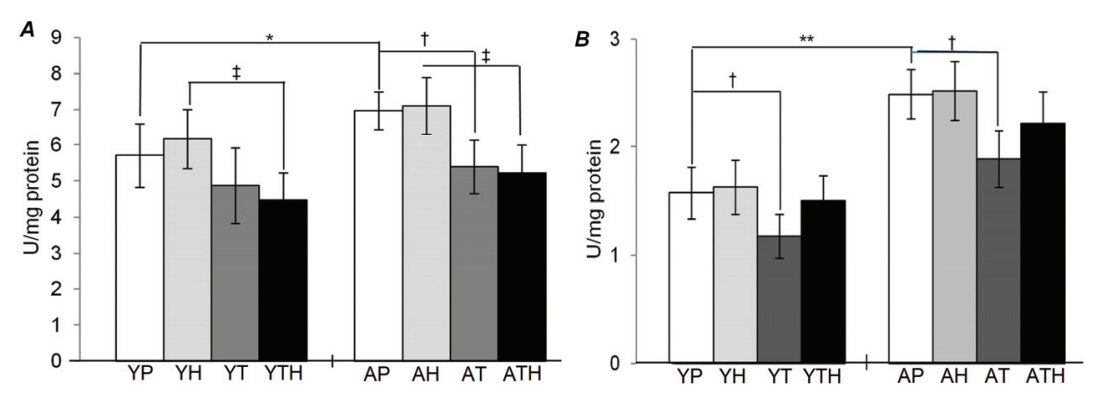

Fig. 1. MnSOD activity in liver $(\boldsymbol{A})$ and brain (B) mitochondria (MnSOD, mean $\pm \mathrm{SE})$. YP young placebo heat unexposed; $\mathrm{YH}$ - young heat exposed; YT - young a-tocopherol treated heat unexposed; YTH - young a-tocopherol treated heat-exposed; AP - aged heat unexposed; $\mathrm{AH}$ - aged heat-exposed; AT - aged a-tocopherol treated and ATH - aged a-tocopherol treated heat-exposed rats. ${ }^{*}$ effect of aging, ${ }^{\dagger}$ effect of a-tocopherol treatment, ${ }^{\ddagger}$ effect of a-tocopherol treatment in heat-exposed rats, ${ }^{*,+, \neq} p<0.05 ;{ }^{* *} p<0.001$.

Fig. 2. GPx activity in liver (A) and brain (B) mitochondria (GPx, mean \pm $\mathrm{SE})$. Abbreviations for groups are the same as in Figure 1, ${ }^{*}$ effect of aging, ${ }^{\dagger}$ effect of a-tocopherol treatment, ieffect of heat exposure, ${ }^{*},+$, I $p<0.05 ;{ }^{* *} p<0.001$.
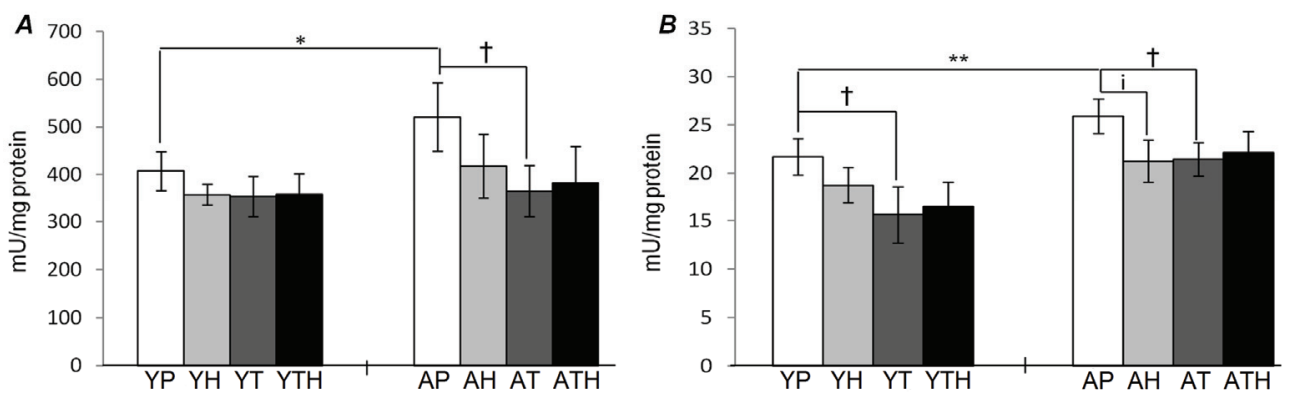
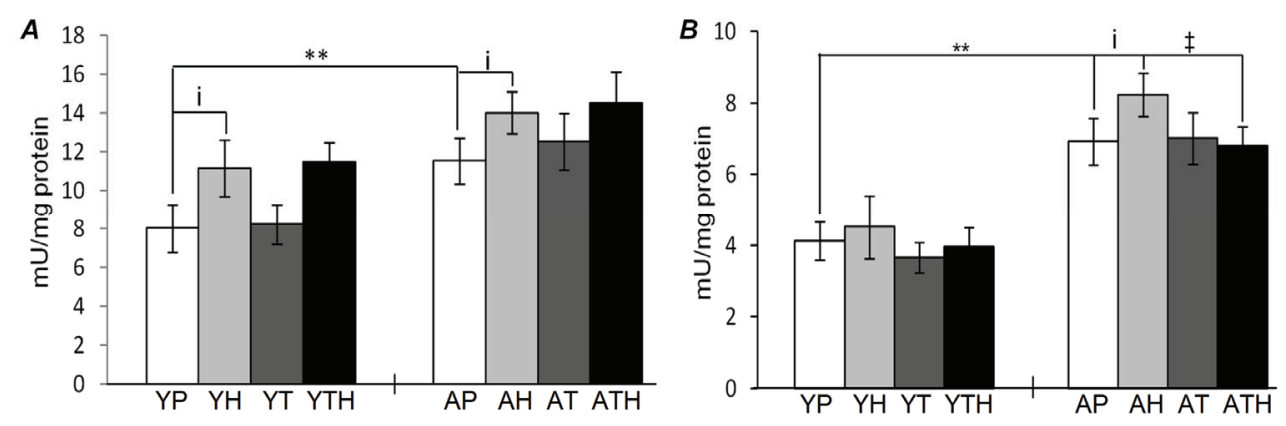

Fig. 3. GR activity in liver $(\boldsymbol{A})$ and brain $(\boldsymbol{B})$ mitochondria (GR, mean $\pm \mathrm{SE}$ ). Abbreviations for groups are the same as in Figure 1, * effect of aging, ${ }^{\ddagger}$ effect of a-tocopherol treatment in heat-exposed rats, ${ }^{i}$ effect of heat exposure, $i, \neq \quad p<0.05$; ${ }^{* *} p<0.001$.

Table 2. Multiple regression analysis of GPx activity in relation to SOD as an index of oxidation.

\begin{tabular}{lcccc}
\hline $\begin{array}{l}\text { Dependent Variable/ } \\
\text { Oxidation indices }\end{array}$ & adjusted $\boldsymbol{r}^{2}$ & $\boldsymbol{p}$ & $\begin{array}{c}\text { Determinant } \\
\text { variable* }\end{array}$ & $\boldsymbol{\beta}$ \\
\hline$A T$ (Liver GPx) & 0.311 & $<0.025$ & SOD & 0.50 \\
$Y T$ (Brain GPx) & 0.341 & $<0.030$ & SOD & 0.53 \\
$A T$ (Brain GPx) & 0.371 & $<0.028$ & SOD & 0.56 \\
\hline
\end{tabular}

* Explanatory variable used in the regression analysis was: mitochondrial level of SOD (superoxide dismutase). Dependent variable is GPx (glutathione peroxidase). YT - young a-tocopherol treated; AT - aged a-tocopherol treated.

\section{Multiple regression analysis}

In order to define relationship between GPx and GR enzyme activity and MnSOD activity as an index of oxidation that precede consequent activation of the above enzymes in mitochondrial level (Wallace 2005), multiple regression analysis was performed with baseline GPx and GR enzyme activity as dependent variable. These results are detailed in Table 2 and show that mitochondrial MnSOD activity determine changes in GPx activity only at $\alpha$-tocopherol: AT liver mitochondria (adjusted $\mathrm{r}^{2}=0.311, \mathrm{p}<0.025$ and $\beta=0.50$ for MnSOD), YT brain mitochondria (adjusted $\mathrm{r}^{2}=0.341, \mathrm{p}<0.030$ and $\beta=0.53$ for MnSOD) and AT brain mitochondria (adjusted $r^{2}=0.371$, $p<0.028$ and $\beta=0.56$ for MnSOD). 


\section{Discussion}

Although many investigators have studied heat and age-related changes in mitochondrial antioxidant defense, results are still controversial (Rikans and Hornbrook 1997). For this reason, we tried to find what happens with the mitochondrial enzymatic antioxidant line during heat exposure in two different aging settings.

In our study, mitochondrial MnSOD activity did not change significantly as a consequence of heat exposure. Actually, in our opinion applied protocol of heat stress is not long enough to induce such a huge production of superoxide that will overwhelm mechanisms responsible for its neutralization. On the contrary, Djordjevic et al. (2010) suggested that oxidation as a consequence of heat exposure can be initiated at this stage, especially if subsequent protective enzyme GPx does not work in sequence with the MnSOD. On the other hand, we observed heat-induced deterioration of GPx activity in mitochondria of aged rats, while GR activity was significantly increased in the aged brain and both liver mitochondria. This relationship between GR and GPx, especially in aged mitochondria, indicates for impaired removal of $\mathrm{H}_{2} \mathrm{O}_{2}$ by GPx. One possible explanation is the high GPx dependence from glutathione (GSH) for its activity, so decreasing of the hepatic GSH level with aging, shown from (Liu et al. 2002), may partly be responsible for the lowered GPx activity. Moreover, the renewable capacity of tissues for GSH could become very weak with the aging, which can be an additional reason for GPx injury during acute heat exposure (Liu et al. 2002).

The treatment with $\alpha$-tocopherol caused significant decrease in both GPx and MnSOD activity in the liver and brain mitochondria of the aged rats. These, $\alpha$-tocopherol induced changes in the activity of GPx can be explained by changes in the activity of MnSOD only in the liver mitochondria of the aged rats. Such a role of $\alpha$-tocopherol is supported by data about subcellular distribution of $\alpha$-tocopherol, indicating that liver's mitochondrial fraction contains higher concentrations of $\alpha$-tocopherol than brain's (Murphy and Mavis 1981). Concerning the changes in GPx activity, as a consequence of $\alpha$-tocopherol, our regression model shows that MnSOD can be taken as a determinant variable of GPx in both young and aged brain mitochondria. These results can be explained by an inverse relationship between the concentration of $\alpha$-tocopherol and GPx activity in rat brain mitochondria (Murphy and Mavis 1981). Further, we did not observe significant $\alpha$-tocopherol influence on GR activity in both liver and brain mitochondria from young and in liver mitochondria from aged rats. In this direction, Iqbal and coworkers (2002) also have shown that $\alpha$-tocopherol has no effect on GR activity in lung mitochondria. This insignificant effect was additionally corroborated by our regression model, which do not support association between the changes in MnSOD and GR activity. On the other hand, prevented GR activity in the presence of $\alpha$-tocopherol was outlined only in the aged heat exposed brain mitochondria. Tretter and Adam-Vizi (2000), suggested that such prevention is a reflection of $\alpha$-tocopherol inhibited GSH depletion.

In summary, the beneficial effect of the treatment with $\alpha$-tocopherol was observed mainly in prevention of heat-induced alterations in the enzyme activities within aged groups. We showed that influenced antioxidant enzymes by intensive production of ROS, especially in liver mitochondria of aged rats, cannot be fully ameliorated by $\alpha$-tocopherol. Taking into account the changes of the studied enzyme activities in the brain mitochondrial level, we assume that the ameliorative effect of $\alpha$-tocopherol is more potentiated on the GPx activity. Actually the fact that our regression model supported determination characteristic of MnSOD only at treated rats and only in relation to GPx, clearly indicate that the relation between these two enzymes is a reflection of $\alpha$-tocopherol prevented GSH depletion. On the other hand, particularly lowered GR activity in comparison to the GPx activity in brain's mitochondrial compartment in our study, indicated that the activity of this enzyme is more important in ameliorative red-ox processes in the same mitochondria.

\section{Conflict of Interest}

There is no conflict of interest.

\section{Acknowledgements}

We wish to thank Prof. Anton Kossev from the Institute of Biophysics, Bulgarian Academy of Sciences in Sofia for assistance with manuscript preparation. We acknowledge the financial support from the Ss. Cyril and Methodius University in Skopje. 


\section{References}

APRILLE JR, AUSTIN J: Regulation the mitochondrial adenine nucleotide pool size. Arch Biochem Biophys 212: 689699, 1981.

AYDIN AF, KUCUKGERGIN C, ÖZDEMIRLER-ERATA G, KOCAK-TOKER N, UYSAL M: The effect of carnosine treatment on prooxidant-antioxidant balance in liver, heart and brain tissues of male aged rats. Biogerontology 11: 103-109, 2010.

BERG BM, GODBOUT JP, KELLEY KW, JOHNSON RW: $\alpha$-tocopherol attenuates lipopolysaccharide-induced sickness behavior in mice. Brain Behav Immun 18: 149-157, 2004.

CARRETERO M, ESCAMES G, LÓPEZ LC, VENEGAS C, DAYOUB JC, GARCÍA L, ACUÑA-CASTROVIEJO D: Long-term melatonin administration protects brain mitochondria from aging. J Pineal Res 47: 192-200, 2009.

CHOW CK, IBRAHIM W, WEI Z, CHAN AC: $\alpha$-tocopherol regulates mitochondrial hydrogen peroxide generation. Free Radic Biol Med 27: 580-587, 1999.

DEL MAESTRO RF, MCDONALD W, ANDERSON R: Superoxide dismutase, catalase and glutathione peroxidase in experimental and human brain tumours. In: Oxy. Radicals and Their Scavenger Systems. GREENWALD R, COHEN G (ed), Elsevier Publisher, New York, 1983, pp 16-34.

DJORDJEVIC J, DJORDJEVIC A, ADZIC M, NICIFOROVIC A, RADOJCIC BA: Chronic stress differentially affects antioxidant enzymes and modifies the acute stress response in liver of Wistar rats. Physiol Res 51: 729-736, 2010.

FARISS MW, NICHOLLS-GRZEMSKI FA, TIRMENSTEIN MA, ZHANG JG: Enhanced antioxidant and cytoprotective abilities of $\alpha$-tocopherol succinate is associated with a rapid uptake advantage in rat hepatocytes and mitochondria. Free Radic Biol Med 31: 530-541, 2001.

FARISS MW, ZHANG JG: Vitamin E therapy in Parkinson's disease. Toxicol 189: 129-146, 2003.

GODBOUT JP, BERG BM, KELLEY KW, JOHNSON RW: $\alpha$-Tocopherol reduces lipopolysaccharide-induced peroxide radical formation and interleukin-6 secretion in primary murine microglia and in brain. J Neuroimmuno 149: 101-109, 2004a.

GODBOUT JP, BERG BM, KRZYSZTON C, JOHNSON RW: $\alpha$-tocopherol attenuates NFkB activation and proinflammatory cytokine production in brain and improves recovery from lipopolysaccharide-induced sickness behavior. J Neuroimmunol 169: 97-105, 2004b.

HADZI-PETRUSHEV N, JANKULOVSKI N, HRISTOV K, MLADENOV M: L-2-oxothiazolidine-4-carboxylate influence on age- and heat exposure-dependent redox changes in rat's blood plasma. J Phys Sci 61: 437-442, 2011.

HADZI-PETRUSHEV N, JANKULOVSKI N, MILEV M, FILIPOVSKA P, GAGOV H, GJORGIEVSKA E, MITROV D, SOPI R, HRISTOV K, MLADENOV M: L-2-oxothiazolidine-4-carboxylate influence on ageand heat exposure-dependent peroxidation in rat's liver and kidney. J Therm Biol 37: 361-365, 2012.

IQBAL M, CAWTHON D, BEERS K, WIDEMAN RF, BOTTJE WG: Antioxidant enzyme activities and mitochondrial fatty acids in pulmonary hypertension syndrome (PHS) in broilers. Poul Sci 81: 252-260, 2002.

JAESCHKE H: Glutathione disulfide formation and oxidant stress during acetaminophen-induced hepatotoxicity in mice in vivo: The protective effect of allopurinol. J Pharmacol Exp Ther 255: 935-941, 1990.

KNIGHT TR, KURTZ A, BAJT ML, HINSON JA, JAESCHKE H: Vascular and hepatocellular peroxynitrite formation during acetaminophen induced liver injury: Role of mitochondrial oxidant stress. Toxicol Sci 62: 212-220, 2001.

LAWRENCE RA, BURK RF: Glutathione peroxidase activity in selenium deficient rat liver. Biochem Biophys Res Commun 71: 952-958, 1976.

LIU J, ATAMNA H, KURATSUNE H, AMES BN: Delaying brain mitochondrial decay and aging with mitochondrial antioxidants and metabolites. Ann N Y Acad Sci 959: 133-166, 2002.

LOWRY OH, ROSEBROUGH NJ, FARR AL, RANDALL RJ: Protein measurement with the Folin phenol reagent. J Biol Chem 193: 265-275, 1951. 
MLADENOV M, GJORGOSKI I, STAFILOV T, DURIDANOVA D: Effect of vitamin C on lipid hydroperoxides and carbonyl groups content of rat plasma depending on age and acute heat exposure. $J$ Therm Biol 31: 588-593, 2006.

MLADENOV M, TANSKA V, VITKOVSKA T, GJORGOSKI I, DINEVSKA-KOFKAROVSKA S, STAFILOV T, HRISTOV K, DURIDANOVA D: Evidence for the influence of vitamin C on age- and heat exposuredependent deterioration of biochemical function in rat's liver and kidney. J Therm Biol 33: 431-436, 2008.

MORRISON JP, COLEMAN MC, AUNAN ES, WALSH SA, SPITZ DR, KREGEL KC: Thiol supplementation in aged animals alters antioxidant enzyme activity after heat stress. J Appl Physiol 99: 2271-2277, 2005.

MURPHY D, MAVIS RD: A comparison of the in vitro binding of $\alpha$-tocopherol to microsomes of lung, liver, heart and brain of the rat. Biochim Biophys Acta 663: 390-400, 1981.

OLAFSDOTTIR K, REED DJ: Retention of oxidized glutathione by isolated rat liver mitochondria during hydroperoxide treatment. Biochim Biophys Acta 964: 377-382, 1988.

OZTURK G, AKBULUT G, GUNEV S, ACUNA-CASTROVIEJO D: Age-related changes in the rat brain mitochondrial antioxidative enzyme ratios: Modulation by melatonin. Exp Gerontol 47: 706-711, 2012.

RACKER E: Glutathione reductase from bakers' yeast and beef liver. J Biol Chem 217: 855-865, 1955.

RIKANS LE, HORNBROOK KR: Lipid peroxidation, antioxidant protection and aging. Biochim Biophys Acta 1362: 116-127, 1997.

TRETTER L, ADAM-VIZI V: Inhibition of Krebs cycle enzymes by hydrogen peroxide: A key role of a-ketoglutarate dehydrogenase in limiting NADH production under oxidative stress. J Neurosci 20: 8972-8979, 2000.

WALLACE DC: A mitochondrial paradigm of metabolic and degenerative diseases, aging, and cancer: a dawn for evolutionary medicine. Annu Rev Genet 39: 359-407, 2005.

YEN TC, KING KL, LEE HC, YEH SH, WEI YH: Age-dependent increase of mitochondrial DNA deletions together with lipid peroxides and superoxide dismutase. Free Radic Biol Med 16: 207-214, 1994.

ZHANG JG, NICHOLLS-GRZEMSKI FA, TIRMENSTEIN MA, FARISS MW: Vitamin E succinct protects hepatocytes against the toxic effect of reactive oxygen species generated at mitochondrial complexes I and III by alkylating agents. Chem Biol Interact 138: 267-284, 2001 a.

ZHANG JG, NICHOLLS-GRZEMSKI FA, TIRMENSTEIN MA, FARISS MW: Mitochondrial electron transport inhibitors cause lipid peroxidation- dependent and - independent cell death: Protective role of antioxidants. Arch Biochem Biophys 393: 87-96, 2001 b. 